\title{
Peripheral Sensory Neuropathy and associated factors among adult diabetes mellitus patients in Bahr Dar, Ethiopia
}

\author{
Gashaw Jember ${ }^{1}$, Yayehirad Alemu Melsew², Berihu Fisseha ${ }^{3}$, Kedir Sany ${ }^{1}$, Asmare Yitayeh Gelaw $^{1 *}$ \\ and Balamurugan Janakiraman ${ }^{1}$
}

\begin{abstract}
Background: Diabetic sensory neuropathy is a common form of microvascular complication among diabetic patients. The swiftly growing population of people living with diabetes in Ethiopia and lack of elaborated scientific data on peripheral sensory neuropathy among diabetic population in Ethiopia prompted this work. This study was set out to assess the enormity and associated factors of peripheral sensory neuropathy among diabetes patients attending chronic illness clinic of Felege Hiwot Regional Referral Hospital, Bahr Dar, Northwest Ethiopia.

Methods: An institution based cross-sectional study was conducted at Felege Hiwot Referral Hospital chronic illness clinic using Michigan neuropathy screening instrument tool for diabetic peripheral sensory neuropathy on 408 diabetic patients during 2016. Data were collected using interview, patient record review, anthropometric measurements and physical examination. Both bivariate and multivariate binary logistic regression was employed to identify factors associated with peripheral sensory neuropathy. Odds ratios with their $95 \% \mathrm{Cl}$ and $P$ value less than 0.05 used to determine statistically significant associations.

Results: A total of 368 patients were included with the mean age of $49 \pm 14.3$ years. The overall prevalence of Peripheral Sensory Neuropathy was found to be $52.2 \%$. The major associated factors identified by multivariate analysis were age >50 years: AOR: $3.0 \mathrm{Cl}$ [1.11, 7.89]; overweight and obese: AOR: $7.3 \mathrm{Cl}$ [3.57, 14.99]; duration of DM: AOR: $3.4 \mathrm{Cl}$ [1.75, 6.60]; not involved in physical exercise: AOR: $4.8 \mathrm{Cl}$ [1.90, 7.89]; male gender: AOR: $2.4 \mathrm{Cl}[1.18,5.05]$.

Conclusion: Almost half of the diabetic patients who attended Felege Hiwot regional referral hospital during study period were found to present with peripheral sensory neuropathy. Socio-demographic and bio characteristics like patients age, Body Mass Index, level of physical activity and marital status were significantly associated with diabetic peripheral sensory neuropathy.
\end{abstract}

Keyword: Diabetes peripheral sensory neuropathy (DPSN), Diabetes mellitus, Ethiopia

\section{Background}

Diabetes mellitus $(\mathrm{DM})$ is swiftly emerging health problem in developing countries; like so in Ethiopia. Due to its chronic nature, it causes many debilitating complications including neuropathy, retinopathy, and nephropathy and macro vascular disease [1].

Peripheral sensory neuropathy (PSN) is one of the complications of diabetes and the most common cause of foot

\footnotetext{
* Correspondence: asmphysio@gmail.com

${ }^{1}$ Department of physiotherapy, School of Medicine, College of Medicine and Health Sciences, University of Gondar, Gondar, Ethiopia

Full list of author information is available at the end of the article
}

ulceration and amputations. It involves damage to the nerve fibers or entire nerve cells. Some diabetic peripheral neuropathic patients may have extremely painful symptoms, others may be asymptomatic [2]. So the absence of symptoms may not be equated with absence of neuropathy which leads to risk of developing foot ulcers and amputations resulting huge impact on reducing the health related quality of life of DM patients [3-5].

The global estimates of Diabetic peripheral sensory neuropathy (DPSN) prevalence vary widely from 9.6 to $88.7 \%$ in different populations. This may be attributed to different types of diabetes, existing health care facilities, 
sample selection, different diagnostic criteria used, variable methods etc. [6-8].

Patients with DPSN might suffer from pain and discomfort in the lower extremities, loss or absence of protective sensation in the lower extremities leading to balance problems, risk of foot ulcerations, and a reduced quality of life in adults with diabetes patients [9].

Most of the time nerve damage and DPSN are irreversible. Hence, early screening of DPSN and identifying associated factors is very crucial especially for developing countries with low resource settings and low literacy rate [5].

The most common factors that may influence the DPSN are age, duration of diabetes since diagnosis, poor glycemic control; history of ulcer; education level, smoking habit, drinking alcohol and body mass index directly increases the incidence of DPSN $[7,10,11]$.

However, in North West Ethiopia the prevalence and associated factors of peripheral sensory neuropathy has not yet been elaborated among Northwest Ethiopian diabetic population.

Therefore this study is aimed to assess the prevalence and associated factors of diabetic peripheral sensory neuropathy among adults with diabetes mellitus in Felege Hiwot Regional Referral Hospital, Northwest Ethiopia.

\section{Method}

\section{Study setting}

An Institution based cross-sectional study was conducted from February 2016 to June 30 2016. The study was done at the diabetes unit of chronic illness clinic of Felege Hiwot Referral Hospital, North West Ethiopia.

\section{Study participants}

The study population comprised of diabetic patients who were under routine medical supervision/follow up and attending out-patient diabetic unit of chronic illness clinic of Felege Hiwot Referral Hospital. Both type I and II diabetes mellitus; age $\geq 20$ years were included and those who were seriously ill, DM patients with HIV, leprosy, peripheral nerve injury, bilateral lower extremity amputees were excluded based on medical chart, history and baseline test.

\section{Sample size determination}

The sample size was determined using EPI INFO seven program to estimate a single population proportion based on the following assumptions: $95 \%$ level of confidence interval and 5\% margin of error. The proportion of DPSN among diabetic patients was taken as $41 \%$ from a study done in Mekele, Ethiopia [12]. With $41 \%$ assumption the derived sample size was 371 and an addition of $10 \%$ non response rate made it (n) 408 .

\section{Sampling procedure}

Systematic random sampling technique was used to recruit participants. The pattern of patient flow rate in the diabetic clinic was considered. As a result, the average patient flow rate was known to be 180 per week. The average flow rate was matched with six weeks of data collection period and a total of 1080 diabetic patients were assumed to be available during this period. The sample was taken from relatively small population $(N=1080)$. The patients included in the sample were selected every third interval. The first patient was selected randomly from the first three by a lottery method, and the next patient was interviewed every third interval.

\section{Variables of the study}

The dependent variable was diabetic peripheral sensory neuropathy measured by Michigan neuropathy screening instrument (MNSI) tool. The independent variables included in the study were; Socio-demographic characteristics, behavioral characteristics and clinical characteristics. The intervening and confounding variables which could influence DPSN are oral anti diabetic agents, insulin, glycemic control $\left(\mathrm{HbA}_{1} \mathrm{C}\right)$, foot care practice and cardiovascular comorbidities.

\section{Operational definition}

The diabetic patient has been considered as having peripheral sensory neuropathy if the patients history version of MNSI questionnaire scoreis $\geq 7$ abnormal responses in the legs (feet) and/or if the lower extremity examination version of MNSI scores $\geq 2.5$ in the legs (feet).

\section{Data collection instrument}

A structured questionnaire was prepared for interview to collect the socio-demographic information. Clinical characteristics were collected from the patient records. Patients were diagnosed for sensory neuropathy by using the MNSI tool. This tool consists of two parts, the first part is history version that contains a questionnaire administered by the interviewer and the second part contains physical assessment examination performed by physiotherapists. The physical examination was done by using multiple $10 \mathrm{gm}$ MEDLINE monofilaments for diabetic neuropathy foot test made in USA to detect diminished or loss of sensation. Each monofilaments were used to test a maximum of 10 patients to avoid over diagnosing error resulting from loss of viscoelasticity due to frequent buckling.

A 128 HZ American Diagnostic Corporation (ADC) Tuning fork was used to detect diminished or loss of vibration sense and Reflex hammers were used to elicit ankle reflex/Achilles tendon reflex to detect the quality of stretch reflex pathway function. The English version of Michigan neuropathy screening instrument was 
translated to the local language (Amharic) and again translated back to English by language experts. The original and translated questionnaires were compared and the discrepancies were reviewed and resolved accordingly.

\section{Data collection methods}

Data were collected through face-to-face interviews, patient record interviews and by physical examination. Anthropometric measurements were conducted to measure height and weight of the study subjects. BMI was calculated as $\mathrm{kg} / \mathrm{m}^{2}$ to determine the nutritional status of body composition. Data collection was carried out by a nurse and two other physiotherapists. A 3 days intensive training was given to the data collectors by the principal investigator (GJ) on how to approach the study participants, how to use the questionnaire and guideline, and the techniques of data collection. The investigators closely followed the data collection process and ensured accuracy, completeness and consistency of the collected questionnaire daily.

\section{Data quality control Methods}

To ensure the quality of data and cultural competence of the tool, pretests of data collection tools were carried out on 45 diabetes patients attending Gondar university Hospital Diabetic Clinic prior to actual data collection and those subjects were excluded from the study. After analyzing the pretest results, necessary modifications and corrections were made accordingly before using the tools in the actual survey. Every day the collected questionnaire was checked for clarity, consistency, and completeness by the investigators. Consequently, amendments and corrections were made before the start of the next day's work. Data double entry was done for reliability and correctness with the respective original data. In addition, computer data cleaning was done.

\section{Data analysis}

Data were coded and entered using EPI INFO version 7 and exported to SPSS for windows version 20. Missing values and data cleaning were checked. Descriptive statistics for the presentation of demographic data, including percentage, or mean and standard deviation (SD) was used. Binary logistic regression was used to identify predictors of DPSN among diabetes patients. Variables with a bivariate $P<0.20$ were fitted into multivariate models for controlling the possible effect of confounders, and finally the variables that had significant association with DPSN were identified on the basis of odds ratio (OR), with 95\% confidence interval $(\mathrm{CI})$ and $P<0.05$. The variables were entered into the multivariate model using the backward stepwise (likelihood ratio) method.

\section{Result}

\section{Socio-demographic characteristics}

A total of 368 diabetic patients participated in the study with a response rate of $90.2 \%$. Forty adult diabetic patients who were selected as sample could not participate in the study due to unwillingness, incomplete medical chart and refusing to take baseline test. The mean age of the participants was 49 years $( \pm 14.3)$. Majority of the respondents were males $(58.4 \%)$, were married (80.2\%) and urban dwelling (82.9\%). Many participants were orthodox Christians (61.7\%) and almost One third (33.4\%) of them were governmental employee. The socio-demographic details of the participants have been provided in Table 1 .

\section{The relation between Age of study participants and peripheral senseory neuropathy}

An increasing trend in prevalence of PSN with increasing age was observed (Fig. 1).

\section{Clinical and Behavioral characteristics}

A total of 263 (71.5\%) of study participants were in normal weight category on BMI whereas 105 (28.6\%) participants were overweight or obese. Most (55.4\%) of the participants were type 2 diabetes mellitus. One hundred ninety (51.6\%) of the study participants' were known to be diagnosed with diabetes for less than 10 years and majority (64.9\%) of the participants had no history of hypertension. Most of the participants (92.9\%) were non-smokers and $45.9 \%$ of them reported to have habit of alcohol consumption. The remaining clinical and behavioral details of the participants are presented in Table 2.

\section{Prevalence of DPSN among diabetic patients}

The overall prevalence of diabetic peripheral sensory neuropathy was found to be 192 (52.2\%) among the study population. Among this, the prevalence of DPSN among type1 diabetes patients was found to be $51.2 \%$. The prevalence of DPSN was slightly higher among diabetic women (56.9\%) than men (48.4\%). The prevalence of DPSN based on other socio demographic characteristics are expressed in Table 1.

\section{Factors associated with DPSN}

Variables that were significantly associated with DPSN in bivariate analysis were reentered into multivariate logistic regression model as independent variables for outcome of DPSN. The factors that were identified to be significantly associated with the development of DPSN were; increased age, being overweight or obese, longer duration of DM and lack of physical activity.

Diabetic patients who were 50 and above years old are about four times more likely to have DPSN than younger patients $[\mathrm{AOR}=4.17,95 \% \mathrm{CI}: 1.60 .10 .85]$. Diabetic patients who were not involved in regular physical 
Table 1 Sociodemographic characteristics and prevalence of DPSN of participants at Bahr Dar Felege Hiwot regional referral Hospital, April 2016, $(n=368)$

\begin{tabular}{|c|c|c|c|c|}
\hline \multirow[t]{2}{*}{ Variable } & & \multirow{2}{*}{$\begin{array}{l}\text { Frequency } \\
\text { (\%) }\end{array}$} & \multicolumn{2}{|c|}{ Outcome of DPSN } \\
\hline & & & Yes (\%) & No (\%) \\
\hline \multirow[t]{2}{*}{$\overline{\text { Sex }}$} & Female & $153(41.6)$ & $87(56.9)$ & $66(43.1)$ \\
\hline & Male & $215(58.4)$ & $104(48.4)$ & $111(51.6)$ \\
\hline \multirow[t]{2}{*}{ Residence } & Urban & $305(82.9)$ & $167(54.8)$ & $138(42.2)$ \\
\hline & Rural & $63(17.1)$ & $24(38.1)$ & 39 (61.9) \\
\hline \multirow[t]{4}{*}{ Religion } & Orthodox & $227(61.7)$ & $104(45.8)$ & $123(54.2)$ \\
\hline & Muslim & $115(31.3)$ & $74(64.3)$ & $41(35.7)$ \\
\hline & Protestant & $24(6.5)$ & $12(50)$ & $12(50)$ \\
\hline & Catholic & $2(0.5)$ & $2(100)$ & 0.0 \\
\hline \multirow[t]{2}{*}{ Marital status } & Married & $295(80.2)$ & $158(53.6)$ & $137(46.4)$ \\
\hline & Unmarried & $73(19.8)$ & $34(46.6)$ & 39 (53.4) \\
\hline \multirow[t]{4}{*}{ Educational status } & No formal. & $22(6.0)$ & $15(68.2)$ & $7(31.8)$ \\
\hline & Elementary [1-8] & $44(12)$ & $24(54.5)$ & $20(45.5)$ \\
\hline & High school [9-12] & $142(38.6)$ & $85(59.9)$ & $57(40.1)$ \\
\hline & College and above & $160(43.5)$ & $68(42.5)$ & $92(57.5)$ \\
\hline \multirow[t]{6}{*}{ Occupational status } & Govt. employ & $123(33.4)$ & $43(35.0)$ & $80(38.0)$ \\
\hline & Private employ & $107(29.1)$ & $66(61.7)$ & $41(38.3)$ \\
\hline & Housewife & $35(9.2)$ & $24(70.6)$ & $10(29.4)$ \\
\hline & Unemployed & $12(3.3)$ & $3(25.0)$ & $9(75.0)$ \\
\hline & Farmer & 39 (10.6) & 15 (38.5) & $24(61.5)$ \\
\hline & Others & $53(14.4)$ & $40(75.5)$ & $13(24.5)$ \\
\hline \multirow[t]{4}{*}{ Income } & $<1000$ & $124(33.7)$ & $68(54.8)$ & $56(45.2)$ \\
\hline & 1000-1999 & $27(7.3)$ & $21(77.8)$ & $6(22.2)$ \\
\hline & 2000-2999 & $39(10.6)$ & $20(51.3)$ & $19(48.7)$ \\
\hline & $\geq 3000$ & $178(48.4)$ & $82(46.1)$ & $96(53.9)$ \\
\hline \multirow[t]{2}{*}{ Alcohol consumption } & Yes & $169(45.9)$ & $96(56.8)$ & $73(43.2)$ \\
\hline & No & $199(54.1)$ & $95(47.7)$ & $104(52.3)$ \\
\hline \multirow[t]{2}{*}{ Smoking status } & Yes & $26(7.1)$ & $26(100)$ & 0 \\
\hline & No & $342(92.9)$ & $165(48.2)$ & $177(51.8)$ \\
\hline \multirow[t]{2}{*}{ Type of DM } & Type 1 & $164(44.6)$ & $84(51.2)$ & $80(48.8)$ \\
\hline & Type 2 & $204(55.4)$ & $107(52.5)$ & $97(47.5)$ \\
\hline \multirow[t]{2}{*}{ Duration of DM } & $\leq 10$ yrs & $190(51.6)$ & $56(29.5$ & $134(70.5)$ \\
\hline & $\geq 10 \mathrm{yrs}$ & $178(48.4)$ & $135(75.8)$ & $43(24.2)$ \\
\hline \multirow[t]{2}{*}{ Hypertension } & Yes & $129(35.1)$ & $103(79.8)$ & $26(20.2)$ \\
\hline & No & $239(64.9)$ & $88(36.8)$ & 151 (63.2) \\
\hline
\end{tabular}

activities were eight times more likely to develop DPSN than those who had regular physical exercise program [AOR: 8.2, CI [3.40, 19.56]. Being overweight or obese was found to be alarmingly [AOR: 16.3, CI [6.12, 43.43] associated with PSN. With duration of diabetes; patients living with DM for 10 years and more were found to be at risk of developing PSN about four times AOR: 4.5, CI $[2.07,9.64]$ more than those with duration of DM less than 10 years (Table 3 ).

\section{Discussion}

This study found out that the prevalence of DPSN according to the MNSI patient history version was $36.3 \%$, which is much lesser than prevalence explored by MNSI examination which was $52.2 \%$. The above difference clearly demonstrates the limitations related to patients self perception of symptoms of DPSN and suggest insisting on MNSI examination to be administered regularly during out-patient visit. Similar finding was observed in 


\section{Prevalence of DPSN}

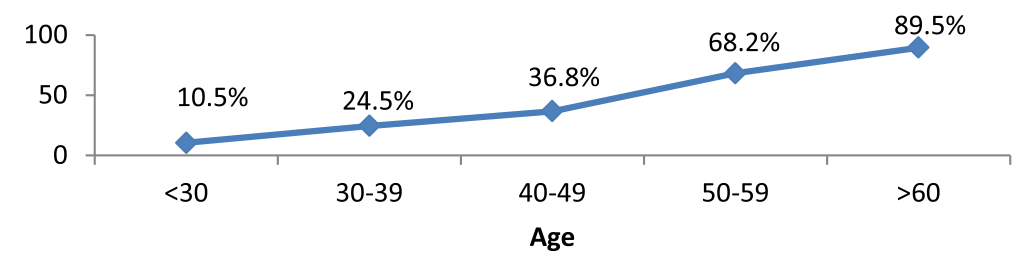

Fig. 1 Trend of DPSN to increase in age among adult diabetic participants at Bahr Dar Felege Hiwot Referral Hospital, 2016, $(n=368)$

a study conducted in Logos Nigeria [13]. The prevalence of DPSN using MNSI examination among adult diabetic participants in.

Bahr Dar Felege Hiwot Regional Referral Hospital was found to be $52.2 \%$ which was more similar to the findings of other studies conducted in Iran and University of Washington, USA $[8,14]$ which reported a prevalence of 53.3 and $50 \%$ respectively. The similarity could be due to the reason that all studies used MSNI examination tool. The prevalence found in this study falls within the range reported by systematic reviews $[12,15,16]$. However, the range reported by those studies was much wider ranging from $26 \%$ to $77 \%$.

The difference in the prevalence of DPSN across the studies maybe attributed to differences in study design, type of population included, resource of hospital set up and type of tool used to assess the magnitude of DPSN in different study settings.

Among studies done in Ethiopia this study reported a higher prevalence of $52.2 \%$ when compared with 41 and

Table 2 Clinical and behavioral characteristics of patients with diabetes mellitus at Bahr Dar Felege Hiwot referral regional Hospital, 2016, Bahr Dar, Ethiopia $(n=368)$

\begin{tabular}{lll}
\hline Variables & $<25$ & Frequency (\%) \\
\hline BMI & $25-29$ & $263(71.5)$ \\
& $\geq 30$ & $26(21.5)$ \\
Types of DM & Type 1 & $164(44.6)$ \\
& Type 2 & $204(55.4)$ \\
Duration of DM & $<10$ & $190(51.6)$ \\
Hypertension & $\geq 10$ & $178(48.4)$ \\
Involved in physical exercise & yes & $129(35.1)$ \\
Alcohol consumption & no & $239(64.9)$ \\
& yes & $98(26.6)$ \\
Smoking status & no & $270(73.4)$ \\
& yes & $169(45.9)$ \\
& no & $199(54.1)$ \\
\hline
\end{tabular}

25\% by studies done in Mekele and Jimma respectively $[17,18]$. The proposed reason could be; the Mekele study was a prospective cohort study detecting only new cases where as this study is a cross sectional one where new and old cases were detected. The Jima study used only a structured questionnaire but this study MSNI history version and examination version which helped identifying more cases. Studies in United Arab Emirates, India, South Africa and Nigeria reported a prevalence of $30.3 \%, 10.5,37,32.2 \%$ respectively $[3,6,7,13]$ which are lower than the prevalence of DPSN in the present study. The possible explanation for the difference in prevalence of DPSN might be the difference in study population, tools used and methodologies. For example, South African study used Douleur neuropathic questionnaire $\left(\mathrm{DN}_{4}\right)$ tool which was different from MNSI tool used in this study and the Nigerian study included diabetes patients diagnosed before five years unlike to the present study which included all the diabetic patients attending at the time of data collection.

Our findings were also lower than the study done in USA (66.7\%), Benin (88.7\%) and Taiwan (71\%) [19-21]. The differences in prevalence could possibly be due to differences in outcome tool and patient characteristics. For instance, the Seattle, USA study used Nerve Conduction Velocity test (NCV) which is a golden standard, costly, time consuming and found in high resource set ups whereas the present study used MNSI tool which is easily applicable and cheap. The study done in Benin used diabetic neuropathy score (DNS) tool and investigated only patients with neuropathic symptoms unlike the present study which investigated all symptomatic and asymptomatic diabetic patients with MNSI. Others studied patients with neurological signs [1, 22] and some studies also combined both neuropathic symptoms and neurological signs similar with this study $[15,17,21]$. Some studies included neurological complications of diabetes patients, motor, sensory and autonomic nerves whereas other authors combined both patients with foot ulcers and peripheral neuropathy $[14,17,18]$. Therefore, the disparities in reported prevalence would have occurred due to factorial differences like type of DM, age group, outcome tools,sample size and socio demographic characteristics of patients. 
Table 3 factors associated with DPSN among diabetic patients at Bahr Dar Felege Hiwot regional referral Hospital by bivariate and multivariate logistic regression analysis, April 2016, Bahr Dar Ethiopia $(n=368)$

\begin{tabular}{|c|c|c|c|c|c|c|c|}
\hline \multirow[t]{2}{*}{ Variable } & & \multicolumn{2}{|c|}{ DPSN (n) } & \multirow{2}{*}{\multicolumn{2}{|c|}{ Crude OR (95\% Cl) }} & \multirow{2}{*}{\multicolumn{2}{|c|}{ AOR $(95 \% \mathrm{Cl})$}} \\
\hline & & Yes & No & & & & \\
\hline \multirow[t]{3}{*}{ Age } & $<40$ & 20 & 86 & 1 & & 1 & \\
\hline & $40-50$ & 44 & 60 & 3.2 & $1.69,5.88$ & $4.2^{\mathrm{a}}$ & $1.60,10.85$ \\
\hline & $>51$ & 127 & 31 & 17.62 & $9.43,32.92$ & $66.1^{\mathrm{a}}$ & $18.59,235.32$ \\
\hline \multirow[t]{2}{*}{ Sex } & Female & 87 & 66 & 1 & & 1 & \\
\hline & Male & 104 & 111 & 0.7 & $0.47,1.08$ & 2.1 & $0.97,4.62$ \\
\hline \multirow[t]{4}{*}{ Educational status } & No formal & 15 & 7 & 0 & & 0 & \\
\hline & Grade 1-8 & 24 & 20 & 2.776 & $1.063,7.251$ & 2.122 & $0.571,7.886$ \\
\hline & Grade 9-12 & 85 & 57 & 1.666 & $0.851,3.260$ & 1.786 & $0.740,4.312$ \\
\hline & College \& a & 68 & 92 & 1 & & 1 & \\
\hline \multirow[t]{4}{*}{ Income } & $<1000$ & 68 & 56 & 1.422 & $0.897,2.253$ & 1.861 & $0.643,5.384$ \\
\hline & 1000-1999 & 21 & 6 & 4.098 & $1.578,10.637$ & 3.986 & $0.822,19.328$ \\
\hline & 2000-2999 & 20 & 19 & 1.232 & $0.616,2.466$ & 1.628 & $0.456,5.806$ \\
\hline & $\geq 3000$ & 82 & 96 & 1 & & 1 & \\
\hline \multirow[t]{2}{*}{ Physical exercise } & yes & 71 & 26 & 1 & & 1 & \\
\hline & no & 106 & 165 & 4.3 & $2.57,7.16$ & $8.2^{a}$ & $3.40,19.56$ \\
\hline \multirow[t]{2}{*}{ Alcohol consumption } & yes & 96 & 73 & 1.440 & $0.953,2.174$ & 1.155 & $0.555,2.406$ \\
\hline & no & 95 & 104 & 1 & & 1 & \\
\hline \multirow[t]{2}{*}{ Duration of DM } & $<10$ yrs & 56 & 134 & 1 & & 1 & \\
\hline & $\geq 10 \mathrm{yrs}$ & 135 & 43 & 7.5 & $4.73,11.95$ & $4.5^{\mathrm{a}}$ & $2.07,9.64$ \\
\hline \multirow[t]{2}{*}{ Hypertension } & yes & 103 & 26 & 6.798 & $4.106,11.254$ & 0.898 & $0.289,2.793$ \\
\hline & no & 88 & 151 & 1 & & 1 & \\
\hline \multirow[t]{3}{*}{ BMI } & $<25$ & 100 & 163 & 1 & & 1 & \\
\hline & $25-29$ & 69 & 10 & 11.3 & $5.54,22.84$ & $16.3^{\mathrm{a}}$ & $6.12,43.43$ \\
\hline & $\geq 30$ & 22 & 4 & 9.0 & $3.00,26.77$ & $28.4^{\mathrm{a}}$ & $6.47,124.28$ \\
\hline
\end{tabular}

${ }^{\text {a Significantly associated with } p<0.05}$

After conducting multivariate logistic regression, we observed that age above 50 years were found to be significantly associated with the development of DPSN. Which is imilar to findings reported in studies conducted in University of Alfenas, Brazil, Fasa University, Hamedan province, Iran, Ethiopia, Benin, USA, Nigeria respectively $[5,10,14,15,21,23,24]$. Aging is a well known risk factor for many non-communicable diseases including DM and increasing age is a risk factors for many neurological disorder, probably reflecting the limited regenerative capacity of the nervous system after any insult. The effect of aging combined with deleterious effects of chronic hyperglycemia can result in increased prevalence of DPSN as one gets older. Other possible reasons could be; peripheral nerve system by their length and size are known to have increased vulnerability with aging due to continual metabolic stress and degenerative nature of physiological well-being.

In the present study, for those who did not involve in physical exercise (sedentary life style) was found to be significantly associated with the development of DPSN in multivariate analysis. Similar findings were observed in studies conducted in Brazil and India [25, 26], However no such association was observed in other studies conducted in India, Iran, Benin, Taiwan $[10,14,20,21]$ The reason behind might be physical exercise can increase micro-vascular circulation, prevent aging, boosts immune system, gives strength to muscle and cardiovascular system as well as physiological well-being of the body so as to negatively affect the occurrence of DPSN.

Increased body mass index was significantly associated with the development of DPSN in diabetes patients in multivariate analysis. This is comparable to the results of studies in South Africa, Ethiopia, Logos, Nigeria, Taiwan USA, UAE [6, 7, 18-20, 26]. The authors also reported that co morbid like hypertension, peripheral vascular diseases and increasing BMI by itself can proportionally increase the risk of DPSN among DM patients.

Duration of diabetes mellitus for more than 10 years were found to be significantly associated with the development 
of DPSN in diabetic patients in multivariate analysis. Similar to the findings obtained in Iran, India and Brazil [19, 20, 26] respectively. Longer duration or chronic hyper glycaemia might result in glycosylation of nervous tissue and therefore damage. Smoking was not significantly associated with DPSN in this study. Only $7.1 \%$ of the participants reported as smokers. But all of them were found to have DPSN. This might be due to small number of smokers in the study population. Unlike the present study, most of the studies done $[9,25,27]$ on the developments of DPSN reported association with the cigarette smoking.

Unlike the present study, low education level, low income, ethnicity being black, presence of hypertension, and male gender were significantly associated with the incidence of DPSN in studies done in Iran, Benin, Bangladesh, Taiwan, and Ethiopia respectively [12, 18, $20,21,26]$. The possible reason behind this might be the methodology of the study, study area, and difference in sample size of the study.

\section{Limitation}

This study certainly has few limitations like sample size being not enormous; which was evident by wider confidence interval. Golden standard diagnostic procedure like Nerve Conduction Velocity Test (NCV) was not performed due to non-affordability.

The effects of intervening and confounding variables like oral anti diabetic agents, insulin, glycemic control $\left(\mathrm{HbA}_{1} \mathrm{C}\right)$, foot care practice and cardiovascular comorbidities on DPSN were not studied.

\section{Conclusions}

This study shows high prevalence of DPSN that almost half of diabetes mellitus patients had experiences DPSN.

Among diabetes patients older age (above $>50$ years); body mass index $\left(>25 \mathrm{~kg} / \mathrm{m}^{2}\right)$; male gender; longer duration of DM and not doing physical exercise were found to be significant factors associated with development of DPSN.

It is worthwhile if Physiotherapists and other health care professionals have an integrated, multidisciplinary and need based approach to prevent DPSN and if comprehensive examination of sensory neuropathy is included as an integral part of DM care. It is also vital that patients living with diabetes mellitus follow regular physical exercise in order to reduce the incidence of DPSN.

\begin{abstract}
Abbreviations
BMI: Body mass index; DM: Diabetics mellitus; DPSN: Diabetic periphera sensory neuropathy; MNSI: Michigan neuropathy screening instrument; NCVT: Nerve Conduction Velocity Test; PSN: Peripheral sensory neuropathy
\end{abstract}

\section{Acknowledgments}

Firstly, we would like to express our deepest gratitude to the University of Gondar for ethical approval and funding. Our gratitude and appreciation goes to data collectors and study participants. We are also very grateful to Felege hiwot regional and Referral Hospital Diabetic Clinic, and the staff.

\section{Funding}

The total budget and other necessary equipments were totally funded by University of Gondar.

\section{Availability of data and materials}

The datasets supporting the conclusions of this article is available in the GitHub repository in https://github.com/Asmare/peripheral-sensory-neuropathyamong-DM-patients/issues/new.

\section{Author contributions}

GJ brought the original idea, was involved in the proposal writing, designed the study, and participated in all the implementation stages of the project. GJ also analyzed the data and wrote the manuscript. YA and BF participated in the conception of the original idea, was involved in the proposal writing, finalized the write-up of the manuscript, and critically revised the manuscript for important intellectual content. BJ, KS and AY were responsible for critically revising the research proposal and the manuscript, and participated in its design and interpretation. AY was involved in the design of the work and approved the version to be published. All the authors read and approved the final version of the manuscript.

\section{Competing interests}

The authors report no competing interest in this work

Consent for publication

Not Applicable

Ethical approval and consent to participate

Ethical approval was secured from the Ethical Review Committee of the College of Medicine and Health Sciences, University of Gondar, Ethiopia. Permission to conduct the research was obtained from Bahr Dar Felege Hiwot Regional Referral Hospital chronic illness clinic, Ethiopia.

\section{Publisher's Note}

Springer Nature remains neutral with regard to jurisdictional claims in published maps and institutional affiliations.

\section{Author details}

'Department of physiotherapy, School of Medicine, College of Medicine and Health Sciences, University of Gondar, Gondar, Ethiopia. ${ }^{2}$ Department of Epidemiology and Biostatistics, Institute of Public Health, College of Medicine and Health Sciences, University of Gondar, Gondar, Ethiopia. ${ }^{3}$ Department of Physiotherapy, School of Medicine, College of Health Sciences and Ayder comprehensive specialized Hospital, Mekelle University, Mekelle, Ethiopia.

Received: 8 December 2016 Accepted: 12 March 2017

Published online: 04 April 2017

\section{References}

1. Leehey DJ, Moinuddin I, Bast JP, Qureshi S, Jelinek CS, Cooper C, et al. Aerobic exercise in obese diabetic patients with chronic kidney disease: a randomized and controlled pilot study. Cardiovasc Diabetol. 2009;8(1):1.

2. Balducci S, lacobellis G, Parisi L, Di Biase N, Calandriello E, Leonetti F, et al. Exercise training can modify the natural history of diabetic peripheral neuropathy. J Diabet Complicat. 2006;20(4):216-23.

3. D'Souza M, Kulkarni V, Bhaskaran U, Ahmed H, Naimish $H$, Prakash A, et al. Diabetic peripheral neuropathy and its determinants among patients attending a tertiary health care centre in Mangalore, India. J Public Health Res [Internet]. 2015 [cited 2016 Dec 3];4(2). Available from: http://www.ncbi. nlm.nih.gov/pmc/articles/PMC4568420/.

4. Hassan Jafari PhD PT, Forugh B. Do diabetic neuropathy patients benefit from balance training? J Rehabil Res Dev. 2012;49(2):333.

5. lunes DH, Rocha CB, Borges NC, Marcon CO, Pereira VM, Carvalho LC. Self-care associated with home exercises in patients with type 2 diabetes mellitus. PLoS One. 2014;9(12):e114151.

6. Jacovides A, Bogoshi M, Distiller LA, Mahgoub EY, Omar MK, Tarek IA, et al. An epidemiological study to assess the prevalence of diabetic peripheral neuropathic pain among adults with diabetes attending private and institutional outpatient clinics in South Africa. J Int Med Res. 2014; 300060514525759 
7. Al-Kaabi JM, Al Maskari F, Zoubeidi T, Abdulle A, Shah SM, Cragg P, et al. Prevalence and determinants of peripheral neuropathy in patients with type 2 diabetes attending a tertiary care center in the United Arab Emirates. J Diabetes Metab [Internet]. 2014 [cited 2016 Dec 3];2014. Available from: http://www.omicsonline.org/open-access/prevalence-and-determinants-ofperipheral-neuropathy-in-patients-with-type-diabetes-2155-6156.1000346. php?aid=24491

8. Sobhani S, Asayesh H, Sharifi F, Djalalinia S, Baradaran HR, Arzaghi SM, et al. Prevalence of diabetic peripheral neuropathy in Iran: a systematic review and meta-analysis. J Diabetes Metab Disord. 2014;13(1):1.

9. Jung C-H, Jung S-H, Kim B-Y, Kim C-H, Kang S-K, Mok J-O. Association of serum omentin levels with cardiac autonomic neuropathy in patients with type 2 diabetes mellitus: a hospital-based study. Cardiovasc Diabetol. 2015;14(1):1.

10. Bansal D, Gudala K, Muthyala H, Esam HP, Nayakallu R, Bhansali A. Prevalence and risk factors of development of peripheral diabetic neuropathy in type 2 diabetes mellitus in a tertiary care setting. J Diabetes Investig. 2014;5(6):714-21.

11. Raval A, Dhanaraj E, Bhansali A, Grover S, Tiwari P. Prevalence \& determinants of depression in type 2 diabetes patients in a tertiary care centre. 2010 [cited 2016 Dec 3]; Available from: http://imsear.li.mahidol.ac.th/handle/123456789/135563.

12. Tesfaye S, Chaturvedi N, Eaton SE, Ward JD, Manes C, lonescu-Tirgoviste C, et al. Vascular risk factors and diabetic neuropathy. N Engl J Med. 2005; 352(4):341-50

13. Ogbera AO, Adeleye O, Solagberu B, Azenabor A. Screening for peripheral neuropathy and peripheral arterial disease in persons with diabetes mellitus in a Nigerian University Teaching Hospital. BMC Res Notes. 2015;8(1):533.

14. Adler Al, Boyko EJ, Ahroni JH, Stensel V, Forsberg RC, Smith DG. Risk factors for diabetic peripheral sensory neuropathy: results of the Seattle prospective diabetic foot study. Diabetes Care. 1997;20(7):1162-7.

15. Hall V, Thomsen RW, Henriksen O, Lohse N. Diabetes in Sub Saharan Africa 1999-2011: epidemiology and public health implications. A systematic review. BMC Public Health. 2011;11(1):1.

16. Stein C, Eibel B, Sbruzzi G, Lago PD, Plentz RD. Electrical stimulation and electromagnetic field use in patients with diabetic neuropathy: systematic review and meta-analysis. Braz J Phys Ther. 2013;17(2):93-104.

17. Gill G, Gebrekidan A, English P, Wile D, Tesfaye S. Diabetic complications and glycaemic control in remote North Africa. QJM. 2008;101(10):793-8.

18. Gudina EK, Amade ST, Tesfamichael FA, Ram R. Assessment of quality of care given to diabetic patients at Jimma University Specialized Hospital diabetes follow-up clinic, Jimma, Ethiopia. BMC Endocr Disord. 2011;11(1):1.

19. Singleton JR, Smith AG, Bromberg MB. Increased prevalence of impaired glucose tolerance in patients with painful sensory neuropathy. Diabetes Care. 2001;24(8):1448-53.

20. Yang C-P, Lin C-C, Li C-I, Liu C-S, Lin W-Y, Hwang K-L, et al. Cardiovascular Risk Factors Increase the Risks of Diabetic Peripheral Neuropathy in Patients With Type 2 Diabetes Mellitus: The Taiwan Diabetes Study. Medicine (Baltimore) [Internet]. 2015 [cited 2016 Dec 3];94(42). Available from: http://www.ncbi.nlm.nih. gov/pmc/articles/PMC4620799/.

21. Thierry A, Philomène K-N, Justine SB, Abdoulaye I, Dismand H. Frequency of Distal Sensory Polyneuropathy among Diabetics in Parakou in 2012. Neurosci Med. 2015;6(3):90.

22. Ugoya SO, Echejoh GO, Ugoya TA, Agaba El, Puepet FH, Ogunniyi A Clinically diagnosed diabetic neuropathy: frequency, types and severity. J Natl Med Assoc. 2006;98(11):1763.

23. Ghodsi R, HamayeliMeharbani H, Avand A-Q, Bordbar A, Ahmadzadeh S. A study on the prevalence of diabetic complications in fasa diabetes clinic. Asian J Med Pharm Res. 2014:4(1):68-72.

24. Kiani J, Azizkhani $H$, Kosarifard S. The prevalence and associated risk factors of peripheral diabetic neuropathy in Hamedan, Iran. Arch Iran Med. 2013;16(1):17.

25. Kärvestedt L, Martensson E, Grill V, Elofsson S, von Wendt G, Hamsten A, et al. The prevalence of peripheral neuropathy in a population-based study of patients with type 2 diabetes in Sweden. J Diabetes Complications. 2011;25(2):97-106.

26. Kiani J, Azizkhani H, Kosarifard S. The prevalence and associated risk factors of peripheral diabetic neuropathy in Hamedan. Iran Arch Iran Med. 2013;16(1):17.

27. Rahimdel A, Afkhami-Ardekani M, Souzani A, Modaresi M, Mashahiri MR. Prevalence of sensory neuropathy in type 2 diabetic patients in Iranian population (Yazd province). Iran J Diabetes Obes. 2009;1(1):30-5.

\section{Submit your next manuscript to BioMed Central and we will help you at every step:}

- We accept pre-submission inquiries

- Our selector tool helps you to find the most relevant journal

- We provide round the clock customer support

- Convenient online submission

- Thorough peer review

- Inclusion in PubMed and all major indexing services

- Maximum visibility for your research

Submit your manuscript at www.biomedcentral.com/submit
C) Biomed Central 